\title{
BMJ Open Epidemiology of healthcare harm in New Zealand general practice: a retrospective records review study
}

\author{
Sharon Leitch (1) , ${ }^{1}$ Susan Dovey, ${ }^{1}$ Wayne Cunningham, ${ }^{2}$ Katharine Wallis, ${ }^{3}$ \\ Kyle Eggleton, ${ }^{4}$ Steven Lillis, ${ }^{5}$ Andrew McMenamin, ${ }^{6}$ Martyn Williamson, ${ }^{1}$ \\ David Reith, ${ }^{7}$ Ariyapala Samaranayaka, ${ }^{8}$ Murray Tilyard ${ }^{1}$
}

To cite: Leitch S, Dovey S, Cunningham W, et al. Epidemiology of healthcare harm in New Zealand general practice: a retrospective records review study. BMJ Open 2021;11:e048316. doi:10.1136/ bmjopen-2020-048316

- Prepublication history and additional supplemental material for this paper are available online. To view these files, please visit the journal online (http://dx.doi.org/10.1136/ bmjopen-2020-048316).

Received 11 January 2021 Accepted 24 June 2021

Check for updates

(C) Author(s) (or their employer(s)) 2021. Re-use permitted under CC BY-NC. No commercial re-use. See rights and permissions. Published by BMJ.

For numbered affiliations see end of article.

Correspondence to

Dr Sharon Leitch;

sharon.leitch@otago.ac.nz

\section{ABSTRACT}

Objectives To determine the epidemiology of healthcare harm observable in general practice records.

Design Retrospective cohort records review study.

Setting 72 general practice clinics were randomly selected from all 988 New Zealand clinics stratified by rurality and size; 44 clinics consented to participate. Participants 9076 patient records were randomly selected from participating clinics.

Intervention Eight general practitioners examined patient records (2011-2013) to identify harms, harm severity and preventability. Analyses were weighted to account for the stratified sampling design and generalise findings to all New Zealand patients.

Main outcome measures Healthcare harm, severity and preventability.

Results Reviewers identified 2972 harms affecting 1505 patients aged $0-102$ years. Most patients (82.0\%, weighted) experienced no harm. The estimated incidence of harm was 123 per 1000 patient-years. Most harms (2160; 72.7\%, 72.4\% weighted) were minor, 661 (22.2\%, $22.8 \%$ weighted) were moderate, and 135 (4.5\%, 4.4\% weighted) severe. Eleven patients died, five following a preventable harm. Of the non-fatal harms, 2411 (81.6\%, $79.4 \%$ weighted) were considered not preventable. Increasing age and number of consultations were associated with increased odds of harm. Compared with patients aged $\leq 49$ years, patients aged 50-69 had an OR of 1.77 (95\% Cl 1.61 to 1.94$), \geq 70$ years OR 3.23 (95\% Cl 2.37 to 4.41). Compared with patients with $\leq 3$ consultations, patients with 4-12 consultations had an OR of 7.14 (95\% Cl 5.21 to 9.79 ); $\geq 13$ consultations OR 30.06 $(95 \% \mathrm{Cl} 21.70$ to 41.63$)$.

Conclusions Strategic balancing of healthcare risks and benefits may improve patient safety but will not necessarily eliminate harms, which often arise from standard care. Reducing harms considered 'not preventable' remains a laudable challenge.

\section{INTRODUCTION}

Audited hospital records in the USA publicised early measures of errors and harm associated with patient care. ${ }^{1}$ Despite thousands of subsequent related publications over the past three decades, patients' experiences of harm across health systems, including primary care,

\section{Strengths and limitations of this study}

- Large, detailed, retrospective general practice records review.

- Stratified design accounts for the heterogeneity of the New Zealand population.

- Patient perspective prioritised in interpretation of harm.

Determination of harm subjective, although measures were taken to improve reviewer consistency.

are still largely unknown. ${ }^{2}$ Existing studies of routinely recorded data from primary care settings around the world provide widely variable estimates of patient harm. ${ }^{3}$

Population-based research is needed to understand the full spectrum of healthcare harm. This will quantify the burden of harm relative to unharmed patients, identify patient risk factors for harm and ascertain circumstances that are high-risk for harm, enabling an appropriate focus on prevention. The records review method can provide research data about populations accessing healthcare. This method is feasible in primary care where records are electronic and patients' contacts throughout the health system are recorded. ${ }^{4-7}$

In this study, we aimed to estimate the incidence, distribution, severity and preventability of patient harms in New Zealand, and to identify risk factors for harm from the whole-of-health-system perspective afforded by electronic health records in general practice clinics.

\section{METHODS}

Setting

New Zealand is a country of 4.9 million people. General practices provide the bulk of primary healthcare and act as a gateway to hospital care and some allied health services. General practitioners and practice nurses 
comprise most of the workforce. Practices receive capitated government funding based on the demographic profile of their patients; patients also contribute a fee-forservice co-payment. Electronic health records have been used in New Zealand general practices for over three decades. They are a repository of comprehensive information about each patient's interactions with the health system, including general practice clinic notes, investigations, prescriptions and summaries of other healthcare received (such as hospital discharge summaries and secondary care reviews).

\section{Design}

The study design is a stratified, two-level cluster, retrospective cohort review of New Zealand general practice electronic health records. ${ }^{89}$ Patient records were randomly selected from consenting practices that were randomly selected after stratification by practice size and location. Three years of patient records were reviewed (2011-2013, inclusive).

\section{Patient and public involvement}

Patients or the public were not involved in the design, recruitment, conduct, reporting or dissemination of our research. Study clinics were advised of the analysis of data from their clinic, with comparison data presented from other similar clinics.

\section{Clinic selection}

Ministry of Health data were used to identify all 988 general practice clinics that received capitation public funding for the first quarter of 2014, where a total of 4289001 people $(95.4 \%$ of the 2014 national population) were registered as patients. Practices were classified as large, medium or small by enrolled patient numbers, divided into tertiles. Practices were also classified as rural or urban by address. Combinations of these practice size and practice location classifications formed six strata. Twelve practices from each stratum (72 practices) were randomly selected and invited to participate; 44 practices consented to participate. A review of the characteristics of the participating general practices found that they were relatively homogeneous, apart from size and location. ${ }^{9}$

\section{Patient selection and electronic records}

Based on our feasibility study, we estimated 1345 patients per strata were needed to identify $5 \%$ difference in harm rates between strata. ${ }^{8}$ To allow for some patients receiving no healthcare during the study period, we aimed to study 1500 patients per stratum ( 9000 patients in total). Patients were randomly selected from participating practices at the mid-point of the 3-year study period, 1 July 2012. All patients enrolled on that date were eligible for selection, regardless of age, health status or any other characteristic.

The electronic health records of these patients for the study period were collated by the study's bespoke electronic data extraction program. This software redacted names and addresses. Study reviewers only had access to extracted records following redaction. The records contained demographic data (age, sex, ethnicity and socioeconomic deprivation level), free-text consultation notes, laboratory and radiology requests and results, alerts and prescriptions. Electronically stored referrals, clinic letters and hospital discharge summaries were also extracted and reviewed whenever available.

\section{Reviewers}

Reviews were conducted by eight clinically active general practitioners with a minimum of 10 years' experience. Reviewer training sessions were held at the commencement of the study. Feedback from double-reviewed files $(948 / 9076,10.4 \%)$ was used to further improve reviewer consistency. The range of agreement between pairs of reviewers was $66.7 \%-100.0 \%$; overall kappa $=0.344$, $\mathrm{p}<0.001$. Differences between reviewers were discussed, and consensus agreement was obtained to determine the final recorded outcome for the double-reviewed files.

Reviewers read the entire records and identified episodes where patients experienced harm. They assessed harm severity and preventability. Harms were recorded in descriptive form. Two investigators (SD, S Leitch) coded harms using the Medical Dictionary for Regulatory Activities (MedDRA) V.18.0 codes. ${ }^{10}$

\section{Analysis}

Each record represented a unique patient. Age, sex, ethnicity and socioeconomic deprivation describe the demography of study patients. Number of general practice consultations, practice size and practice location were included as explanatory variables in the univariate and multivariable logistic regression models. Logistic regression explored gradients of harm across each variable by using 'experienced at least one harm' as the binary outcome. Univariate analysis was completed first (unadjusted), and multivariable analysis adjusted for possible confounding effects among all variables. Incidence rates were calculated as the number of events divided by the total number of person-years of follow-up (eg, $3 * 9076$ years, 3 years per person). All analyses were completed in Stata statistical software V.15.1 using the 'svy' suite of commands with study-design-based sampling weights so that results are generalisable to the New Zealand population. Unweighted analyses have been provided for comparison. Cases with missing data were excluded only from the multivariable analysis. The authors had access to all of the statistical reports and tables.

\section{Variables}

Harm

Harm was defined as "physical, emotional or financial negative consequences to patients directly arising from healthcare, beyond the usual consequences of care, and not attributable to patients' health conditions. ${ }^{, 811}$ All patient files were reviewed by at least one of the eight clinician researchers, who identified harms from longitudinal patient records, and 


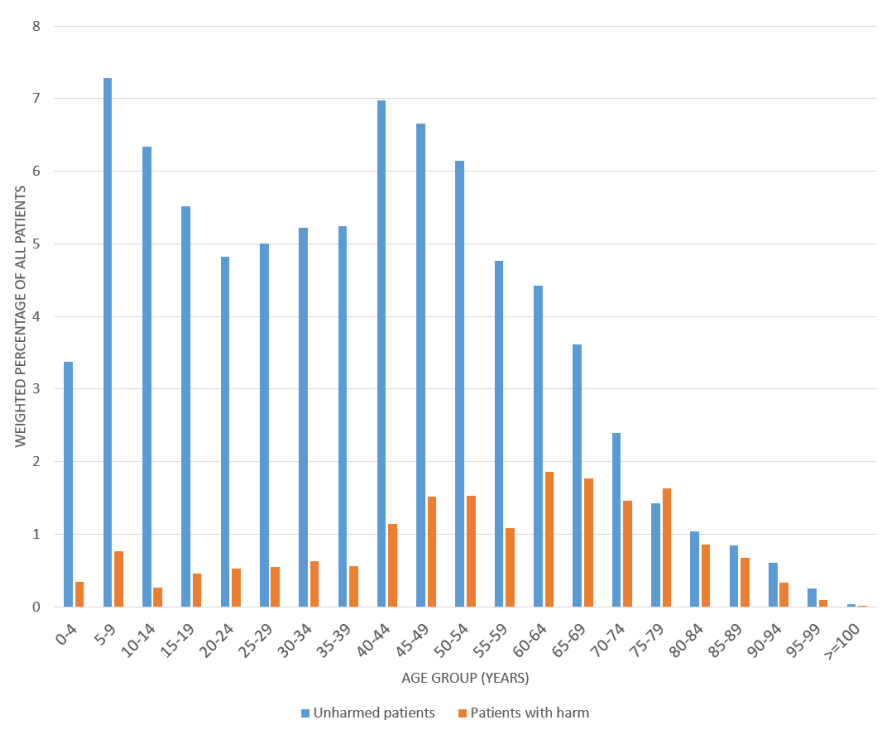

Figure 1 Patient distribution by age group.

assessed their severity and preventability. Medical errors were not studied. ${ }^{10}$

\section{Harm severity}

Reviewers assessed harm severity by considering whether each harm led to additional general practice visits or treatments, emergency department visits or hospital admissions. Severity options were 'minor', 'moderate', 'severe' or 'death.' ${ }^{8}$ Relatively trivial harms that were short-lived were coded minor (eg, thrush, nausea and patient inconvenience, such as being given the wrong prescription). Harms with increased or persistent morbidity were coded moderate (eg, fractures, unplanned pregnancy and poor diabetic control). Severe harms included events such as myocardial infarction, renal failure and morphine overdose.

\section{Harm preventability}

Following McKay et $a l^{12}$ reviewers used their clinical expertise to assess harm preventability from five options. After researcher discussion and consensus, these options were aggregated in analysis to 'preventable or potentially preventable' (original codes: 'preventable and originated in primary care' and 'potentially preventable and originated in primary care') and 'not preventable' ('not preventable, standard treatment,' 'not preventable and originated in primary care,' 'not preventable and originated in secondary care' and 'preventable and originated in secondary care OR not preventable and originated in primary care').

\section{Ethnicity}

Although New Zealanders can identify with multiple ethnicities, prioritised ethnicity is used in the health sector and this study. ${ }^{13}$ Ethnicity is recorded by each practice at time of patient enrolment. Ethnicity data were missing for 144 out of 9076 patients (1.6\%).

\section{Socioeconomic status}

The New Zealand Deprivation Index (NZDep) ${ }^{14}$ is a national meshblock level index but used as a proxy for individual socioeconomic status. We used NZDep13 (based on the 2013 census) quintiles, where 1=least deprived and $5=$ most deprived. ${ }^{15}$ Our data abstraction process captured the NZDep relevant to each patient's address without downloading the addresses themselves. NZDep was missing for 894 out of 9076 patients $(9.9 \%)$.

\section{Grouping}

Age and number of consultations were grouped for improved clinical relevance in terms of identifying patients at increased risk of harm. Age was sorted into three groups: 0-49 years, 50-69 years and 70+ years. Number of consultations with a general practitioner, practice nurse or nurse practitioner during the 3-year study period were sorted into three groups: low (0-3 consultations), moderate (4-12 consultations) and high healthcare users (13+ consultations).

\section{RESULTS}

Over the three study years, the 9076 study patients had 115797 unique general practice visits, 212963 prescriptions of 833 different pharmaceuticals and 2578 hospital admissions. Patients were aged $<1$ year $(n=9)$ to $>100$ years $(n=7)$, with a bimodal age distribution typical of general practice consulting populations. Reviewers identified 2972 harms experienced by 1505 patients. After applying weighting, the incidence rate of harm was 123 harms per 1000 patient-years, and the incidence rate of preventable or potentially preventable harm was 26 harms per 1000 patient-years. Figure 1 shows the weighted patient distribution of harmed and unharmed patients by age group, calculated as a percentage of total number of patients. Table 1 shows the demographic profile of the study sample, both unweighted and weighted for extrapolation to the New Zealand population.

Older age and having more general practice visits were associated with a significantly increased risk of harm (table 2 and online supplemental table 1). Compared with patients aged $<50$ years, older patients had increased odds of experiencing one or more healthcare harm; 50-69 years OR 1.77 (95\% CI 1.61 to 1.94 ), >70 years OR 3.23 (95\% CI 2.37 to 4.41 ). Increasing exposure to healthcare was associated with increased likelihood of experiencing harm. Compared with patients with $\leq 3$ general practice consultations over the three study years, patients with more consultations had increased odds of experiencing one or more harms; 4-12 consultations OR 7.14 (95\% CI 5.21 to 9.79 ), >13 consultations OR 30.06 (95\% CI 21.70 to 41.63$)$.

Among patients experiencing harm, 831 (55.2\%, 54.5\% weighted) had one harm, $329(21.9 \%, 20.5 \%$ weighted $)$ had two harms and 345 (22.9\%, 25.0\% weighted) patients had three or more harms. Median age increased with 
Table 1 Characteristics of patients with no harm and harm, number of general practice visits, and size and location of general practices

\begin{tabular}{|c|c|c|c|c|c|}
\hline & & Patients with no harm & Patients with harm & Patients with no harm & Patients with harm \\
\hline & & \multicolumn{2}{|l|}{ Unweighted study data } & \multicolumn{2}{|l|}{ Weighted data* } \\
\hline Totals N (\%) & & $7571(83.4)$ & $1505(16.6)$ & 3475547 (82.0) & 764745 (18.0) \\
\hline \multirow{2}{*}{$\begin{array}{l}\text { Gender } \\
\text { (missing=0) }\end{array}$} & Female & 3899 (81.7) & $873(18.3)$ & $1817380(80.0)$ & $453441(20.0)$ \\
\hline & Male & 3672 (85.3) & $632(14.7)$ & $1658167(84.2)$ & $311305(15.8)$ \\
\hline \multirow{5}{*}{$\begin{array}{l}\text { Age, years } \\
\text { (missing=0) }\end{array}$} & Range & $0-105$ & $1-102$ & $0-105$ & $1-102$ \\
\hline & Median (IQR) & $39(18-56)$ & $61(45-74)$ & $38(17-54)$ & $58(41-71)$ \\
\hline & $0-49$ years & 4991 (91.2) & $482(8.8)$ & 2390556 (89.3) & $285314(10.7)$ \\
\hline & $50-69$ years & $1858(77.9)$ & $528(22.1)$ & 804646 (75.3) & 264595 (24.8) \\
\hline & $70+$ years & $722(59.3)$ & $495(40.7)$ & $280345(56.6)$ & $214837(43.4)$ \\
\hline \multirow{4}{*}{$\begin{array}{l}\text { Ethnicity } \\
\text { (missing=144) }\end{array}$} & NZ European & 5669 (82.3) & $1220(17.7)$ & 2691696 (80.8) & $638381(19.2)$ \\
\hline & Māori & $1144(86.3)$ & $182(13.7)$ & $362522(84.7)$ & $65288(15.3)$ \\
\hline & Pasifika & $277(86.7)$ & 39 (12.3) & $94893(88.3)$ & $12619(11.7)$ \\
\hline & Other & $364(90.8)$ & $37(9.2)$ & $287550(87.8)$ & $39834(12.3)$ \\
\hline \multirow{5}{*}{$\begin{array}{l}\text { Deprivationt } \\
\text { (missing=894) }\end{array}$} & 1 & $1651(84.0)$ & $315(16.0)$ & $1085488(82.5)$ & 230902 (17.5) \\
\hline & 2 & $1530(82.2)$ & $332(17.8)$ & $761198(80.2)$ & $187988(19.8)$ \\
\hline & 3 & $1434(84.3)$ & $267(15.7)$ & $625564(84.2)$ & $117447(15.8)$ \\
\hline & 4 & 1129 (83.4) & $225(16.6)$ & $439218(81.3)$ & $101032(18.7)$ \\
\hline & 5 & $1072(82.5)$ & 227 (17.5) & 355921 (80.4) & 86823 (19.6) \\
\hline \multirow{5}{*}{$\begin{array}{l}\text { Number of } \\
\text { consultations } \\
\text { (missing=0) }\end{array}$} & Range & $0-136$ & $1-183$ & $0-136$ & $1-183$ \\
\hline & Median (IQR) & $7(2-14)$ & $25(15-38)$ & $7(3-14)$ & $22(13-36)$ \\
\hline & $0-3$ & 2445 (98.8) & $29(1.2)$ & 1072837 (98.7) & $14343(1.3)$ \\
\hline & $4-12$ & 2964 (91.8) & $264(8.2)$ & $1406534(90.0)$ & $156117(10.0)$ \\
\hline & $13+$ & 2162 (64.1) & $1212(35.9)$ & 996176 (62.6) & $594286(37.4)$ \\
\hline \multirow[t]{3}{*}{ Practice size } & Large & 2480 (82.6) & $523(17.4)$ & $2240802(80.9)$ & $527613(19.1)$ \\
\hline & Medium & 2518 (81.8) & $562(18.3)$ & 854347 (82.6) & $180597(17.5)$ \\
\hline & Small & 2573 (86.0) & $420(14.0)$ & 380398 (87.1) & 56535 (12.9) \\
\hline \multirow[t]{2}{*}{ Practice location } & Urban & 3810 (83.9) & 734 (16.2) & 2830637 (81.7) & $636100(18.4)$ \\
\hline & Rural & 3761 (83.0) & $771(17.1)$ & 644911 (83.4) & $128646(16.6)$ \\
\hline
\end{tabular}

*Weighting was applied based on the relative probability of each person being selected to participate due to the complex sampling design of the study.

†Deprivation is based on NZDep index of socioeconomic deprivation, where $1=$ least deprived, 5=most deprived.

increasing number of harms. Patients with three or more harms experienced 3-15 harms (median 4; IQR 3-6).

The majority of harms were considered not preventable (2420/2972, 81.4\%, 79.2\% weighted). Most harms (2160; $72.7 \%, 72.4 \%$ weighted) were considered minor, but 661 (22.2\%, 22.8\% weighted) were of moderate severity, and 135 (4.5\%, 4.4\% weighted) severe (table 3). Fortyfive patients were hospitalised; the estimated incidence of hospitalisation was 2.3 per 1000 patient-years. Eleven patients died as a result of harm: for five of those patients, their harms were considered potentially preventable. The estimated incidence of death was 0.5 per 1000 -patient years. Of the patients who died, four had one harm, two patients had two harms, three patients had three harms and two had four harms. Table 3 shows the severity and preventability of harms, with examples in each category.

\section{DISCUSSION}

Most patients did not experience harm identifiable from their medical records; however, we estimate an incidence rate of 123 harms per 1000 patient-years. Despite most harm being considered minor, general practice records reveal the extent of severe harms, including preventable deaths. Older people experienced more harm, irrespective of their number of consultations. Having more medical encounters was also associated with increased risk of harm, regardless of age. Harm was not found to be associated with patient gender, ethnicity, socioeconomic deprivation or the size or location of the general practice.

\section{Strengths and limitations}

This paper describes data from a large, New Zealandwide sample of patient records, providing insight into 
Table 2 Risk factors for experiencing harm

\begin{tabular}{|c|c|c|}
\hline & $\begin{array}{l}\text { Adjusted and weighted } \\
\text { OR (95\% Cl) }\end{array}$ & $P$ value \\
\hline \multicolumn{3}{|l|}{ Age } \\
\hline $0-49$ years & 1 (Reference) & - \\
\hline $50-69$ years & 1.77 (1.61 to 1.94$)$ & $<0.001$ \\
\hline$\geq 70$ years & 3.23 (2.37 to 4.41$)$ & $<0.001$ \\
\hline \multicolumn{3}{|l|}{ Gender } \\
\hline Male & 1 (Reference) & - \\
\hline Female & $1.11(0.78$ to 1.58$)$ & 0.538 \\
\hline \multicolumn{3}{|l|}{ Ethnicity } \\
\hline European & 1 (Reference) & - \\
\hline Māori & 1.00 (0.78 to 1.27$)$ & 0.992 \\
\hline Pasifika & 0.81 (0.47 to 1.40$)$ & 0.438 \\
\hline Other & 0.89 (0.69 to 1.14$)$ & 0.346 \\
\hline \multicolumn{3}{|l|}{ Deprivation } \\
\hline 1 & 1 (Reference) & - \\
\hline 2 & 1.10 (0.84 to 1.43$)$ & 0.486 \\
\hline 3 & 0.83 (0.61 to 1.12$)$ & 0.209 \\
\hline 4 & 1.01 (0.81 to 1.25$)$ & 0.935 \\
\hline 5 & 1.02 (0.69 to 1.50$)$ & 0.924 \\
\hline \multicolumn{3}{|l|}{ Consultations } \\
\hline $0-3$ & 1 (Reference) & - \\
\hline $4-12$ & 7.14 (5.21 to 9.79$)$ & $<0.001$ \\
\hline$\geqq 13$ & 30.06 (21.70 to 41.63$)$ & $<0.001$ \\
\hline \multicolumn{3}{|l|}{ Practice size } \\
\hline Large & 1 (Reference) & - \\
\hline Medium & 0.82 (0.58 to 1.17$)$ & 0.273 \\
\hline Small & 0.71 (0.50 to 1.01$)$ & 0.059 \\
\hline \multicolumn{3}{|c|}{ Practice Location } \\
\hline Urban & 1 (Reference) & - \\
\hline Rural & $0.76(0.57$ to 1.00$)$ & 0.051 \\
\hline
\end{tabular}

harm patients' experienced in general practice and in other healthcare settings. ${ }^{4}$ The whole-of-healthcare lens afforded by this method follows patients' healthcare journeys across settings, identifying in one setting delayed harm arising from care in another. The stratified design allowed heterogeneity of the population be accounted for in a probabilistic manner.

Medical records contain both healthcare providers' observations and reports of patients' experiences-but only if patients tell their healthcare provider and that experience is documented. Clinicians frequently disregard minor harms an acceptable consequence of care (eg, nausea with antibiotics), and ignore patient inconvenience and expense. However, we have privileged patients' experiences, interpreting these recorded events as being serious enough to call 'harm' using a broad patientfocused definition. ${ }^{811}$ We acknowledge more patients experienced harm than was recorded. Not all reported harm would be recorded, and many patients face access barriers both to receive care and to report harm. ${ }^{16-18}$

The records review method has been criticised for lack of reliability and reproducibility ${ }^{19}{ }^{20}$ : we consider it is the best method we have available to obtain a general (if imperfect) assessment of patient harm across the health system. We attempted to address issues of reliability with reviewer training in the early phases of the study; our kappa value was calculated from the double-reviewed files used for training.

\section{Comparison with literature}

No directly comparable studies have been published. Our focus on all harms is unique-similar studies typically focus on preventable harms such as medical error or patient safety incidents. ${ }^{51} 22$ Our method is comprehensive-other studies examine records only from patients considered at high-risk of experiencing harm, thus missing harms experienced by low-risk patients. ${ }^{21-23}$ Published studies to date provide vastly different measures and rates of harm, likely attributable to differences in definitions and methods. ${ }^{34}$

We estimate an incidence rate of 123 harms per 1000 patient-years, with approximately $20 \%$ of those harms considered preventable or potentially preventable. These rates are substantially higher than other general practice record review studies. Gaal et a $\tilde{b}$ identified 58 per 1000 patients affected by patient safety incidents over 1 year in the Netherlands, Tsang $e t a l^{24}$ examined general practice Read codes to find surgical and medical injury in 0.72 per 1000 consultations and adverse drug reactions in 1.26 per 1000 consultations annually in England, Madden et $a l^{23}$ found harms in $19.1 \%$ of patient records selected by a trigger tool in Northern Ireland and the Republic of Ireland, while in England Avery $e t a l^{22}$ found a rate of avoidable significant harm was 35.6 per 100000 patientyears after examining the records of high-risk patients. We posit our rates of harm are higher than all these studies because of our broad definition of harm, our examination of all patient records (not just records of patients considered high risk or identified by a trigger tool), and the comprehensive content of the electronic health records we reviewed.

Our other major findings are consistent with extant literature. The majority of harms observed were of minor severity and were considered not preventable. This is consistent with other studies of patient safety in primary care. ${ }^{522} 25$ Older patients and patients having more consultations were at increased risk of harm in our study. This is understandable; people who have more clinical encounters have more potential for harm, and increasing multimorbidity and polypharmacy with age and over time is a well-recognised phenomenon. ${ }^{26-28}$ We also found practice size and location were not associated with increased risk of harm, which may be explained by the fact our study practices were relatively homogenous. ${ }^{9}$ Previous studies have shown that practice size and location may affect patient care, but the literature is inconsistent, suggesting 
Table 3 Characteristics of harms by severity and preventability

\begin{tabular}{|c|c|}
\hline Preventability & Examples \\
\hline \multicolumn{2}{|c|}{ Minor severity 2160 harms, $72.7 \%$ of all harms $\left(72.4 \%\right.$ weighted $\left.{ }^{\star}\right)$} \\
\hline $\begin{array}{l}\text { Not preventable } \\
1819,84.2 \% \\
(83.2 \% \text { weighted })\end{array}$ & $\begin{array}{l}\text { A } 75 \text {-year-old man developed a widespread rash and nausea while taking a course of } \\
\text { flucloxacillin. } \\
\text { A 63-year-old woman developed headaches attributed to methotrexate use, which } \\
\text { resolved with cessation of methotrexate. }\end{array}$ \\
\hline $\begin{array}{l}\text { Potentially preventable } \\
341,15.8 \% \\
\text { (16.8\% weighted) }\end{array}$ & $\begin{array}{l}\text { A 36-year-old woman was unable to receive results from secondary care infertility } \\
\text { investigations without making an appointment to see her General Practitioner. } \\
\text { An } 84 \text {-year-old man had a 3-week delay for a Needs Assessment because the incorrect } \\
\text { form was used. }\end{array}$ \\
\hline
\end{tabular}

Moderate 661 harms, $22.2 \%$ of all harms (22.8\% weighted)

$\begin{array}{ll}\text { Not preventable } & \text { A 26-year-old woman experienced excessive vaginal bleeding after Jadelle subcutaneous } \\ 492,74.4 \% & \text { contraceptive implant was inserted, necessitating surgical removal. } \\ \text { (70.2\% weighted) } & \text { A 16-year-old boy developed depression after commencement of doxycycline, which } \\ & \text { resolved on cessation. }\end{array}$

Potentially preventable

$169,25.6 \%$

(29.8\% weighted)

In the months following a terminal cancer diagnosis, an 83-year-old man failed to receive support from hospice or community care, resulting in hospital admission due to general decline.

A 67-year-old man was hospitalised with a gastric bleed after long-term use of diclofenac and aspirin without gastric protection.

Severe 135 harms, $4.5 \%$ of all harms (4.4\% weighted)

$\begin{array}{ll}\text { Not preventable } & \text { A 20-year-old woman became pregnant while taking the combined contraceptive pill. } \\ 100,74.0 \% & \text { A 57-year-old woman experienced anaphylactic shock after preoperative administration of } \\ (62.6 \% \text { weighted }) & \text { intravenous cefazolin prior to surgery. } \\ \text { Potentially preventable } & \text { Delayed diagnosis of sexual abuse in an 8-year-old girl who had multiple presentations } \\ 35,25.9 \% & \text { with urine infection and abdominal pain. } \\ (37.4 \% \text { weighted }) & \text { A 57-year-old woman developed a staphylococcal septic arthritis following a steroid joint } \\ & \text { injection. }\end{array}$

Death 16 harms resulting in the death of 11 people, $0.5 \%$ of all harms $(0.4 \%$ weighted $)$

$\begin{array}{ll}\begin{array}{l}\text { Not preventable } \\ 9,56.3 \%\end{array} & \begin{array}{l}\text { A 74-year-old man experienced a cerebrovascular accident during carotid endarterectomy } \\ \text { and died. }\end{array} \\ \text { (47.8\% weighted) } & \begin{array}{l}\text { An 83-year-old woman prescribed aspirin and clopidogrel died following a haemorrhagic } \\ \text { cerebrovascular accident. }\end{array} \\ \text { Potentially preventable } & \begin{array}{l}\text { A 68-year-old man presented to ED with chest pain relieved by nitrates. He was only } \\ \text { prescribed omeprazole and died following a myocardial infarction } 8 \text { days later. }\end{array} \\ \text { (52.43.8\% weighted) } & \text { A 90-year-old man fell while a patient in hospital and hit his head, sustaining a subdural } \\ & \text { bleed, and dying a few days later. }\end{array}$

*Weighted percentages account for the stratified sampling design.

ED, emergency department.

perhaps continuity of care is more important than practice size or location. ${ }^{29-31}$

\section{Implications}

Our research indicates that 'first, do no harm' is out of step with patients' experience of healthcare. We found that patient harm is common and mostly non-preventable, as it arose from routine care; recognising this should inform shared decision-making when considering investigation and treatment options. However, to accept these harms as inevitable is defeatist, diminishing impetus for change. ${ }^{32}$

The challenge is to reduce the burden of patient harm. ${ }^{32}$ Clinicians need technologies to reduce cognitive load, such as automatic identification of patients at high risk of patient harm, and prescribing and deprescribing support. General practices work relatively autonomously; sector-wide coordination could develop policies, training and patient safety cultural practices that could contribute to safer work systems. Finally, patients should be involved in developing standard measures for patient harm in general practice. This will help focus patient safety measures as well as improve the quality of future research in this area.

\section{CONCLUSION}

This analysis of real-world general practice data increases our understanding of patient harm. Patient harm is common, but was mostly considered minor and 
non-preventable. Strategic balancing of healthcare risks and benefits may improve patient safety but will not necessarily eliminate harms, which often arise from standard care. Reducing patient harm arising from routine care is a difficult but laudable challenge.

\section{Author affiliations}

${ }^{1}$ General Practice and Rural Health, Otago Medical School, University of Otago,

Dunedin, New Zealand

${ }^{2}$ Department of Family Medice, RCSI Bahrain, Manama, Bahrain

${ }^{3}$ Primary Care Clinical Unit, University of Queensland, Brisbane, Queensland, Australia

${ }^{4}$ General Practice and Primary Healthcare, Faculty of Medicine and Health Sciences, University of Auckland, Auckland, New Zealand

${ }^{5}$ Student Health, University of Waikato, Hamilton, New Zealand

${ }^{6} \mathrm{Te}$ Ngae Medical Centre, Rotorua, New Zealand

${ }^{7}$ Office of the Dean, Otago Medical School, University of Otago, Dunedin, New Zealand

${ }^{8}$ Preventive and Social Medicine, Otago Medical School, University of Otago, Dunedin, New Zealand

\section{Twitter Sharon Leitch @dr_leitch}

Acknowledgements Thanks to all the general practices who participated in this work and to Jason Hall from Best Practice Advocacy Centre New Zealand (bpacNZ) Clinical Solutions, who provided IT support for this work.

Contributors S Leitch was a clinical coordinator for the study, recruited the study practices, reviewed general practice records, coded harms, conducted statistical analyses and wrote this manuscript. SL is the guarantor for this research and as corresponding author attests that all listed authors meet authorship criteria and that no others meeting the criteria have been omitted. SD is the Principal Investigator, conceived and undertook the SHARP study design, obtained research funding, coded harms and critically reviewed this manuscript. WC reviewed general practice records, coded harms and critically reviewed this manuscript. DR, KW, KE, AM, MW, S Lillis and MT reviewed general practice records and critically reviewed this manuscript. AS contributed to the study design and critically reviewed this manuscript.

Funding This study was funded by the Health Research Council of New Zealand (HRC-14-185).

Competing interests All authors had financial support from the Health Research Council New Zealand for the submitted work; MT is the CEO of bpacNZ, the company subcontracted to develop the bespoke data extraction software, extract the data, manage the file allocation to reviewers and collate the results for the researchers. DR has received payment from Therapeutic Goods Administrationpayment for consultancy services, and Medsafe and New Zealand Formularypayment for committee and board membership. No other authors have any competing interests to declare; there are no other relationships or activities that could appear to have influenced the submitted work.

\section{Patient consent for publication Not required.}

Ethics approval This study was reviewed by the Minister of Health, the Royal New Zealand College of General Practitioners and the Ngāi Tahu Research Consultation Committee. Ethical approval for this study was obtained from the University of Otago Human Ethics Committee (HD14/32). Consideration of ethical issues pertaining to this study design has been published. ${ }^{33}$

Provenance and peer review Not commissioned; externally peer reviewed.

Data availability statement The ethical approval for this study precludes any sharing of raw data; reasonable requests for deidentified data will be considered.

Supplemental material This content has been supplied by the author(s). It has not been vetted by BMJ Publishing Group Limited (BMJ) and may not have been peer-reviewed. Any opinions or recommendations discussed are solely those of the author(s) and are not endorsed by BMJ. BMJ disclaims all liability and responsibility arising from any reliance placed on the content. Where the content includes any translated material, BMJ does not warrant the accuracy and reliability of the translations (including but not limited to local regulations, clinical guidelines, terminology, drug names and drug dosages), and is not responsible for any error and/or omissions arising from translation and adaptation or otherwise.
Open access This is an open access article distributed in accordance with the Creative Commons Attribution Non Commercial (CC BY-NC 4.0) license, which permits others to distribute, remix, adapt, build upon this work non-commercially, and license their derivative works on different terms, provided the original work is properly cited, appropriate credit is given, any changes made indicated, and the use is non-commercial. See: http://creativecommons.org/licenses/by-nc/4.0/.

ORCID iD

Sharon Leitch http://orcid.org/0000-0001-9939-8773

\section{REFERENCES}

1 Brennan TA, Leape LL, Laird NM, et al. Incidence of adverse events and negligence in hospitalized patients. Results of the Harvard medical practice study I. N Engl J Med 1991;324:370-6.

2 Cooper J, Williams H, Hibbert P, et al. Classification of patient-safety incidents in primary care. Bull World Health Organ 2018;96:498-505.

3 Tsang C, Majeed A, Aylin P. Routinely recorded patient safety events in primary care: a literature review. Fam Pract 2012;29:8-15.

4 Madden C, Lydon S, Curran C, et al. Potential value of patient record review to assess and improve patient safety in general practice: a systematic review. Eur J Gen Pract 2018;24:192-201.

5 Gaal S, Verstappen W, Wolters R, et al. Prevalence and consequences of patient safety incidents in general practice in the Netherlands: a retrospective medical record review study. Implement Sci 2011;6:1-7.

6 Wallis K, Dovey S. No-Fault compensation for treatment injury in New Zealand: identifying threats to patient safety in primary care. BMJ Qual Saf 2011;20:587-91.

7 Phillips RL, Bartholomew LA, Dovey SM, et al. Learning from malpractice claims about negligent, adverse events in primary care in the United States. Qual Saf Health Care 2004;13:121-6.

8 Dovey SM, Leitch S, Wallis KA, et al. Epidemiology of patient harms in New Zealand: protocol of a general practice records review study. JMIR Res Protoc 2017;6:e10.

9 Leitch S, Dovey SM, Samaranayaka A, et al. Characteristics of a stratified random sample of new Zealand general practices. J Prim Health Care 2018;10:114-24.

10 International Council for Harmonisation of Technical Requirements for Pharmaceuticals. Medical dictionary for regulatory activities (MedDRA) distribution file format document version 18.0. Vol MSSODI-6281-18.0.0. 18.0 ed. Geneva: ICH, 2015.

11 Runciman WB. Shared meanings: preferred terms and definitions for safety and quality concepts. Med J Aust 2006;184:S41.

12 McKay J, de Wet C, Kelly M, et al. Applying the trigger review method after a brief educational intervention: potential for teaching and improving safety in GP specialty training? BMC Med EduC 2013;13:117.

13 Stats NZ. Ethnicity New Zealand standard classification statistics New Zealand. classifications and related statistical standards, 2005. Available: http://archive.stats.govt.nz/methods/classifications-andstandards/classification-related-stats-standards/ethnicity.aspx

14 Atkinson J, Salmond C, Crampton P. NZDep2013 index of deprivation. Dunedin: University of Otago, 2014.

15 Ministry of Health. Atlas of socioeconomic deprivation in New Zealand Ministry of health, 2008. Available: https://www.health. govt.nz/publication/dhb-maps-and-background-information-atlassocioeconomic-deprivation-new-zealand-nzdep2006

16 Jatrana S, Crampton P. Primary health care in New Zealand: who has access? Health Policy 2009;93:1-10.

17 Jatrana S, Crampton P, Norris P. Ethnic differences in access to prescription medication because of cost in New Zealand. J Epidemiol Community Health 2011;65:454-60.

18 Metcalfe S, Beyene K, Urlich J, et al. Te Wero tonu-the challenge continues: Māori access to medicines 2006/07-2012/13 update. N Z Med J 2018:131:27-47.

19 van Melle MA, Zwart DLM, Poldervaart JM, et al. Validity and reliability of a medical record review method identifying transitional patient safety incidents in merged primary and secondary care patients' records. BMJ Open 2018;8:e018576.

20 Shojania KG, Marang-van de Mheen PJ. Identifying adverse events: reflections on an imperfect gold standard after 20 years of patient safety research. BMJ Qual Saf 2020;29:265-70.

21 Singh H, Schiff GD, Graber ML, et al. The global burden of diagnostic errors in primary care. BMJ Qual Saf 2017;26:484-94.

22 Avery AJ, Sheehan C, Bell B, et al. Incidence, nature and causes of avoidable significant harm in primary care in England: retrospective case note review. BMJ Qual Saf 2020;0:1-10. 
23 Madden C, Lydon S, Cupples ME, et al. Safety in primary care (SAP-C): a randomised, controlled feasibility study in two different healthcare systems. BMC Fam Pract 2019;20:22.

24 Tsang C, Majeed A, Banarsee R, et al. Recording of adverse events in English general practice: analysis of data from electronic patient records. Inform Prim Care 2010;18:117-24.

25 Panesar SS, deSilva D, Carson-Stevens A, et al. How safe is primary care? A systematic review. BMJ Qual Saf 2016;25:544-53.

26 Nishtala PS, Salahudeen MS. Temporal trends in polypharmacy and Hyperpolypharmacy in older new Zealanders over a 9-year period: 2005-2013. Gerontology 2015;61:195-202.

27 Ferguson CA, Thomson WM, Smith MB, et al. Medication taking in a national sample of dependent older people. Res Social Adm Pharm 2020;16:299-307.

28 Mangin D, Heath I, Jamoulle M. Beyond diagnosis: rising to the multimorbidity challenge. BMJ 2012;344:e3526.
29 Kralewski J, Dowd B, Knutson D, et al. The relationships of physician practice characteristics to quality of care and costs. Health Serv Res 2015;50:710-29.

30 Bankart MJG, Baker R, Rashid A, et al. Characteristics of general practices associated with emergency admission rates to hospital: a cross-sectional study. Emerg Med J 2011;28:558-63.

31 Barker I, Steventon A, Deeny SR. Association between continuity of care in general practice and hospital admissions for ambulatory care sensitive conditions: cross sectional study of routinely collected, person level data. BMJ 2017;356:j84.

32 Pronovost PJ, Sutcliffe KM, Basu L, et al. Changing the narratives for patient safety. Bull World Health Organ 2017;95:478-80.

33 Wallis KA, Eggleton KS, Dovey SM, et al. Research using electronic health records: balancing confidentiality and public good. J Prim Health Care 2018;10:288-91. 